\title{
Entre conflitos e harmonias: 0 assistencialismo empresarial na América Latina
}

\author{
Between class conflict and class cooperation: Company welfare \\ policies in Latin America
}

\section{Andrea Norma Andújar* Silvana A. Palermo*}

Resumo: Este dossiê aborda o assistencialismo empresarial na Argentina, no Chile e no Brasil. Seu objetivo é reconsiderar sua complexidade e relevância, com base em investigações cuja riqueza empírica estimula o debate sobre as categorias com as quais este tema foi conceitualizado: paternalismo, "company welfare", assistencialismo empresarial, entre outros. Trata-se, portanto, de reconstruir alguns dos capítulos da complexa relação entre capital e trabalho nessas nações, em que conflitos e harmonias convergem em espaços de trabalho heterogêneos e diversos atores sociais. O dossiê reúne artigos que, mesmo sem ter deliberadamente visões comparativas, estimulam diálogos entre experiências de diferentes casos nacionais, em diversos ramos produtivos e segmentos de trabalhadores durante o século XX. Reafirma a necessidade de historicizar a vocação empresarial assistencialista através de ensaios, múltiplas iniciativas e processos contingentes, ponderar seu alcance e limites, e reconsiderar a agência histórica, tanto de empresários quanto de trabalhadores. $\mathrm{O}$ dossiê está organizado de acordo com um critério temático - sensível às comparações por tipo de atividade - e ao mesmo tempo cronológico - atento às variações do assistencialismo empresarial em um mundo transformado, mas tão turbulento quanto incerto.

Palavras-chave: assistencialismo empresarial, paternalismo industrial, trabalhadores.

* Doutora em História pela Universidad de Buenos Aires. Investigadora Adjunta do Consejo Nacional de Investigaciones Científicas y Técnicas (CONICET). E-mail: andreaandujar@gmail.com. ORCID: https://orcid. org/0000-0002-5713-9308.

** Doutora em História pela State University of New York at Stony Brook. Professora Titular na Universidad Nacional de General Sarmiento (Buenos Aires, Argentina), Investigadora Adjunta do Consejo Nacional de Investigaciones Científicas y Técnicas (CONICET). E-mail: palermosilvi@gmail.com. ORCID: https://orcid. org/0000-0003-1778-1758. 
Abstract: This dossier gathers eight articles concerned with company welfare plans in Argentina, Chile, and Brazil in the twentieth century. Based on well-researched case studies, they point to the relevance of these programs in the Southern Cone and call attention to their mutable nature. The articles delve into the complex relationship between capital and labor to assess how class conflicts and class cooperation intertwined in the vast diversity of Latin American labor worlds. Although the historical analysis of these studies circumscribes at a local or a national level, the dossier looks for encouraging dialogues and exchanges among scholars interested in comparing and contrasting different national and industrial experiences in this region. The articles remind us of the importance of thinking about industrial paternalism from a historical perspective to recover the trial and error path companies pursued on designing welfare policies toward workers and employees. In the contested process of making these corporative programs, these studies highlight the agency of employers, experts, state officials, white-collar employees, and workers. Lastly, they explore the scope and limitations of these policies in changing economic, social, political, and even cultural conjunctures. In so doing, the dossier invites to rethink how social scientists, particularly historians, conceptualize these policies of extra-salary compensations by revisiting the categories of industrial paternalism, patronage, and company welfare, among others. For its organization, this dossier follows a double criterion. It combines studies that deal with analogous economic sectors in similar historical contexts. At the same time, it underscores the value of assessing changes and continuities in terms of these companies' programs in the unpredictable and turbulent twentieth century.

Keywords: Company Welfare, Industrial Paternalism, Working Class.

D URANTE MUITOS ANOS, as interpretações sobre a industrialização na América Latina enfatizaram seu caráter tardio, a relativa fraqueza (ou mesmo ausência) do empresariado local, a dependência do capital e das tecnologias estrangeiras. O incontestável desenvolvimento de estudos sobre os mundos do trabalho a partir das perspectivas da história social em nossa região, com os avanços no conhecimento das experiências dos trabalhadores, suas formas de protesto e envolvimento político, estimulou revisões sobre esse universo empresarial, suas características, maneiras de organização e associação, suas estratégias e identidades. Nesse percurso, este dossiê aborda uma dimensão desse universo: aquela referente ao assistencialismo empresarial na Argentina, no Chile e no Brasil. Seu objetivo é reconsiderar sua complexidade e relevância, com base em investigações cuja riqueza empírica estimula o debate sobre as categorias com as quais esse tema foi conceitualizado: paternalismo, "company welfare" assistencialismo empresarial, entre outros. Trata-se, portanto, de reconstruir alguns dos capítulos da complexa relação entre capital e trabalho nessas nações, em que conflitos e harmonias convergem em espaços de trabalho heterogêneos e diversos atores sociais. 
O dossiê reúne artigos que, mesmo sem ter deliberadamente visões comparativas, estimulam diálogos entre experiências de diferentes casos nacionais, em diversos ramos produtivos e segmentos de trabalhadores durante o século XX. Reafirma a necessidade de historicizar a vocação empresarial assistencialista através de ensaios, múltiplas iniciativas e processos contingentes, ponderar seu alcance e limites, e reconsiderar a agência histórica, tanto de empresários quanto de trabalhadores. Precisamente, ao questionarem as miríades de formas que assumiram os programas de benefícios extraordinários, esses estudos ultrapassam de dois modos os limites mais próximos e mais imediatos colocados pela experiência no local de trabalho. Por um lado, atentos em alguns casos ao gênero, enfocam a vida laboral cotidiana e seus complexos vínculos, dissolvendo as fronteiras entre a vida comunitária e o local de trabalho, e entre este último e o lar. Por outro lado, põem em jogo escalas locais, nacionais e transnacionais, pois a compreensão das práticas empresariais, seu desenho e implementação, e a forma como os trabalhadores são afetados por elas, exigem colocá-las em contextos sociais, políticos e culturais mais amplos. A articulação entre escalas também evidencia sua utilidade ao propiciar a conceitualização das iniciativas assistenciais e a reflexão acerca da ingerência de especialistas e funcionários públicos sobre elas.

Examinar o assistencialismo a partir dessas perspectivas exige originalidade analítica e metodológica. Os artigos avançam nessa direção com base no exame meticuloso de uma vasta documentação produzida pelas próprias empresas, tais como balanços, arquivos pessoais, atas de diretoria, livros, revistas, histórias corporativas, apresentações em congressos especializados, notas e memorandos de associações patronais e sociedades de socorros mútuos patrocinadas pelas empresas. Além disso, a experiência dos trabalhadores e suas famílias pode ser rastreada na imprensa sindical, partidária e étnica, nas memórias obreiras armazenadas nos Centros de Documentação, nas cartas dos trabalhadores e nos arquivos familiares - papéis e narrativas que facilitam o acesso à voz desses sujeitos de uma forma mais direta, com menos mediação. Os artigos também contemplam análises da documentação produzida por diferentes agências estatais, incluindo arquivos policiais, legislação, estatísticas e resoluções de entidades envolvidas na regulamentação da relacão entre capital e trabalho.

O dossiê está organizado de acordo com um critério temático - sensível às comparações por tipo de atividade - e cronológico - atento às variações do assistencialismo empresarial em um mundo transformado, mas tão turbulento quanto incerto. Começa com dois estudos centrados em cenários portuários - Buenos Aires e Valparaíso -, elaborados, respectivamente, por Laura Caruso e Camilo Santibáñez Rebolledo. Ambos os artigos exemplificam a complexidade da trama patronal portuária e marítima no final do século XIX e nas primeiras décadas do século $X X$, revelando suas respostas aos desafios apresentados por uma classe trabalhadora altamente mobilizada e organizada. A construção de grandes empresas ligadas ao transporte marítimo, atividade estratégica para as economias chilena e argentina, incitou seus líderes empresariais a projetar estratégias precisas, conciliar esforços e homogeneizar 
práticas a fim de enfrentar em melhores condições os trabalhadores, tarefa difícil de ser realizada quando se trata de um setor empresarial diversificado e heterogêneo, como no caso do Chile, e estrangeiro, como no caso da Argentina. Se a heterogeneidade do primeiro resultou, em princípio, em uma política de disciplinamento das próprias fileiras patronais, a condição de estrangeiro do segundo encorajou o uso da etnicidade e da origem nacional dos trabalhadores na delineação das intervenções assistenciais da empresa.

Os três artigos subsequentes, escritos por Silvana Palermo, Andrea Andújar e Guilherme Fernandes Reis das Chagas, concentram-se em experiências em grandes empresas ligadas à atividade ferroviária, à exploração de petróleo e ao serviço de eletricidade na primeira metade do século XX. Nessas empresas, que operavam em larga escala e estavam localizadas em várias regiões da Argentina e do Rio de Janeiro, a profissionalização das gerências e a subsequente organização de departamentos específicos levaram à disponibilidade de recursos para programas assistenciais e iniciativas publicitárias destinadas a difundir valores relativos à disciplina, lealdade e responsabilidade entre operários e empregados. Os três estudos mostram a centralidade da interseção entre as concepções de família promovidas pelas empresas e comunidades laborais e a complexa construção das identidades nacionais e raciais. Também colocam em evidência a crescente incidência de discursos nacionalistas que tentaram superar ou obscurecer a disputa capital-trabalho, situando a harmonia entre classes como uma questão fundamental para a defesa dos interesses da nação e de seu destino político. Todos eles nos lembram que o delineamento das práticas assistenciais e seus significados naquele tempo não podem ser entendidos além daquele mundo em que os Estados constroem nações e pugnam por elas, e até mesmo se tornam patrões.

A conclusão do dossiê compreende uma tríade de estudos sobre a agroindústria açucareira em Tucumán, no noroeste da Argentina, e sobre a indústria têxtil, contemplando duas comunidades operárias ligadas a grandes fábricas localizadas no Rio Grande do Sul e no interior de São Paulo. Elaborados por Florencia Gutiérrez, Caroline Duarte Matoso e Luis Henrique Carboni Junior, esses artigos analisam experiências, trajetórias e memórias de práticas assistenciais e seus protagonistas, tanto empresários como ativistas sindicais, militantes políticos, trabalhadores e suas famílias. As autoras e o autor observam como gravitam nessas práticas e em suas lembranças certos desafios, negociações, consensos e ressignificações na pretensão empresarial de intervir na reprodução das famílias da classe trabalhadora. Ao contrário dos três estudos apresentados na seção anterior, esses trabalhos abordam famílias empresariais cujas iniciativas assistenciais poderiam ser concebidas como um tipo de paternalismo, evidenciado pela associação entre elas e os sobrenomes dos proprietários dessas empresas. Esses artigos também compartilham o interesse em explorar as transformações dessas práticas no contexto do segundo pós-guerra, quando a intervenção estatal e a polarização política, primeiro em termos de democracia vs. fascismo, e depois capitalismo vs. comunismo, confrontaram empregadores e trabalhadores diante de 
novos desafios e um repertório renovado de práticas assistenciais. Em um contexto em que a linguagem dos direitos laborais se generalizou, benefícios concedidos de forma discricionária pelas empresas passaram a ser considerados prerrogativas reconhecidas aos trabalhadores pela autoridade estatal. Certamente, o limite da universalidade de tais direitos esteve no gênero, assim como as possibilidades da classe empresarial de manter a "solidariedade" entre classes em função da reificação do lugar subordinado das trabalhadoras.

Nas últimas décadas, a proliferação de debates sobre uma história global dos trabalhadores estimulou uma produção acadêmica que se renovou em dois sentidos. Por um lado, reforçou-se a vocação de privilegiar o estudo do trabalho em outras regiões do mundo, além da Europa; por outro, aprofundou-se o interesse em reconceitualizar o trabalho para compreender a incidência de formas e relações laborais distintas das do proletariado fabril, mais complexas e substantivas para a reprodução do capitalismo. ${ }^{1}$ Como essa renovação pode afetar nossa visão do assistencialismo empresarial? Primeiramente, a partir da história social dos trabalhadores, avança-se nas fronteiras de nosso conhecimento das práticas empresariais, da produtividade e da especificidade das provas assistenciais, de suas trajetórias e desvios, em uma região da América Latina que, sem desconsiderar a assimetria de poder que a liga ao mundo, exibe não apenas originalidade, mas também um vasto conjunto de singularidades no campo do assistencialismo empresarial. As contribuições reunidas neste dossiê já não permitem continuar pensando nestas práticas assistenciais e em seus programas como meras manifestações tardias, imaturas ou incompletas de experiências acontecidas em países desenvolvidos ou centrais, ou como meras reapropriações das mesmas. Tal ponto de vista mostra que o paternalismo e o "company welfare" deixaram de ser considerados como tipos de intervenção que se sucedem no tempo e são incompatíveis entre si. $^{2}$ Do mesmo modo, permite vislumbrar como os contornos do assistencialismo empresarial podem se sobrepor aos do associacionismo étnico, exigindo uma compreensão de como eles se entrelaçam mutuamente.

Em segundo lugar, outro insumo analítico valioso que propicia o diálogo entre esses diversos casos do sul global refere-se ao reconhecimento das perspectivas, interesses e demandas dos trabalhadores na concepção, implementação e mudanças das políticas assistenciais empresariais. O dossiê recoloca o conflito de classes nesse processo, observando sua historicidade e contingência, não só porque indaga sobre os empresários em termos de suas políticas disciplinares - questão que tem dominado a historiografia - mas também e sobretudo porque busca os trabalhadores e sua agência no contexto de relações de luta e consenso, rastreando interesses contrapostos que também se articulam na encruzilhada das identidades de classe, gênero, racializadas e étnicas.

1 A respeito desses debates, cf. WEINSTEIN, Barbara. Globalizando a História do Trabalho: o caso da revista International Labor and Working-Class History. Revista Mundos do Trabalho, Florianópolis, v. 9, n. 18, p. 1123, 2017.

2 Veja-se REZENDE, Vinícius de. Totalitarismo empresarial: uma análise do sistema Bata no Brasil e no Chile (1940-1970). Revista Mundos do Trabalho, Florianópolis, v. 12, p. 1-33, 2020. 
Finalmente, os estudos deste dossiê são expoentes de uma produção acadêmica que embora não abandone as fronteiras dos espaços nacionais, se interessa por suas singularidades e até se aprofunda em suas diversidades internas e variações locais. É justamente no contraponto desses casos nacionais que se torna possível avançar na construção de um mapa de questões e abordagens históricas compartilhadas, promovendo a convergência de estratégias metodológicas para respondê-las. Desse modo, queremos contribuir para os esforços de um intercâmbio historiográfico regional que começou a disponibilizar frutos há algum tempo. ${ }^{3}$

Por esta razão, gostaríamos de agradecer aos colegas cujos estudos sugestivos tornaram possível este dossiê, a Cristiana Schettini por sua colaboração com a revisão dos artigos, assim como aos editores da revista pelo apoio, especialmente nesse complexo contexto de pandemia. Estamos satisfeitas por terem aceitado esta proposta que, em nossa opinião, está em diálogo direto com a agenda de pesquisa que a Revista Mundos do Trabalho vem delineando, como se pode observar em alguns de seus últimos dossiês e artigos aqui mencionados. Esperamos ter contribuído nessa direção.

Recebido em 17/08/2021

Aprovado em 24/08/2021

3 SURIANO, Juan; SCHETTINI, Cristiana (comp.). Historias cruzadas. Diálogos historiográficos sobre el mundo del trabajo en Argentina y Brasil. Buenos Aires: Teseo, 2019. 